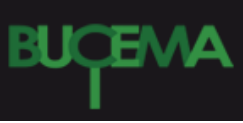

Bulletin du centre d'études médiévales d'Auxerre | BUCEMA

Hors-série $n^{\circ} 7 \mid 2013$

Les nouveaux horizons de l'ecclésiologie : du discours clérical à la science du social

\title{
Las ideas eclesiológico-políticas de Ockham y su nominalismo: reconsiderando una relación problemática
}

\section{Carolina Fernández}

\section{CpenEdition}

\section{Edición electrónica}

URL: https://journals.openedition.org/cem/12776

DOI: $10.4000 /$ cem. 12776

ISSN: 1954-3093

Editor

Centre d'études médiévales Saint-Germain d'Auxerre

Referencia electrónica

Carolina Fernández, «Las ideas eclesiológico-políticas de Ockham y su nominalismo: reconsiderando una relación problemática », Bulletin du centre d'études médiévales d'Auxerre | BUCEMA [En ligne], Horssérie $n^{\circ} 7$ | 2013, mis en ligne le 21 mars 2013, consulté le 02 mars 2023. URL : http:// journals.openedition.org/cem/12776; DOI : https://doi.org/10.4000/cem.12776

Este documento fue generado automáticamente el 2 marzo 2023.

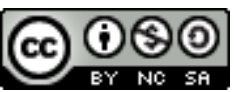

Creative Commons - Attribution - Pas d'Utilisation Commerciale - Partage dans les Mêmes Conditions 4.0 International - CC BY-NC-SA 4.0

https://creativecommons.org/licenses/by-nc-sa/4.0/ 


\title{
Las ideas eclesiológico-políticas de Ockham y su nominalismo: reconsiderando una relación problemática
}

\author{
Carolina Fernández
}

Inscripto en la llamada "teoría política medieval" que floreció en Occidente a partir de fines del siglo XIII en respuesta al conflicto entre el poder espiritual y el poder temporal, el pensamiento eclesiológico-político de Guillermo de Ockham mereció atención creciente durante el siglo xx. Esto fue paralelo a la rehabilitación de Ockham en la esfera de la filosofía y la teología: sus teorías sobre el conocimiento y el lenguaje, sus posiciones en metafísica y filosofía natural o en debates teológicos como los de la justificación y la eucaristía han llegado a tener un papel preponderante en el interés de los principales medievalistas. Los escritos de Ockham (Surrey, 1285 - Munich, 1347) presentan una singularidad: un corte bastante ostensible entre los temas de su Opera Philosophica et Theologica ${ }^{1}$, correspondiente a su desempeño en la universidad entre 1317 y 1324, y su Opera Politica ${ }^{2}$, que reúne lo escrito a partir de su exilio forzado del mundo académico. Inicialmente debido a una citación del papado por cuestiones doctrinales, éste se hizo definitivo a partir de 1328 como consecuencia de su oposición al papa Juan XXII. Entre ambos voluminosos corpus hay un evidente cambio de temas, intereses y fuentes (aunque, ciertamente, se percibe una continuidad de método y lenguaje). Los vaivenes de las tendencias interpretativas han ido, desde intentar reconectarlos de alguna manera, hasta evitar la cuestión misma, analizando cada uno en abstracción del otro. En este trabajo abordaremos otra vez esta problemática clásica, eligiendo como hilo conductor uno de los puntos más característicos de la metafísica ockhamista: el concepto de "relación". Procuraremos mostrar la génesis de las interpretaciones que establecieron una conexión estrecha entre ambos temas; aportar algunas observaciones sobre aspectos no advertidos del tema y, sobre esa base, plantear un programa de trabajo. 


\section{El problema}

Ockham, como hemos dicho, hizo aportes por igual de remarcables a la especulación teórica y a los debates prácticos de la primera mitad del s. xIv. Se ha discutido mucho, sin embargo, si esas dos vertientes reconocen puntos de fuerte convergencia. Parece más bien como si su trayectoria intelectual se hubiera escindido en dos, en respuesta a escenarios bien diferentes. Entre 1317 y 1324 tuvo lugar su desempeño en la universidad, que le valdría posteriormente el epíteto de "Venerable Iniciador de la escuela nominalista": sus ideas filosóficas y teológicas marcarían el pulso de la Universidad europea desde la década de $1330 \mathrm{y}$ por los siguientes cien años. A partir de 1327, cuando el general de su orden, Miguel de Cesena, le mandó estudiar las constituciones de Juan XXII, fue el franciscano comprometido en la cuestión político institucional de la coyuntura. Si se repasan los aportes de Ockham en el primer terreno, resultan impactantes, teniendo en cuenta que los desarrolló en menos de una década y cambiaron sustancialmente el curso del pensamiento de la Baja Edad Media. Ockham afirma, ad nauseam y de modo radical, la singularidad o individualidad de todo lo real, contra toda una tradición dominante de corte realista en materia de universales, aunque de un realismo inmanentista o no platónico. La actitud intelectual que lo define es, ante todo, negativa, en el sentido de que se niega a explicar, fundamentar o dar razón de la individualidad de las cosas mediante cualquier principio de los usualmente ensayados por la tradición filosófica y teológica. Nociones que los autores medievales precedentes habían combinado variadamente, como los pares de conceptos "individuación-naturaleza común", "acto-potencia", "existencia-esencia”, "hipóstasisparticipación”, están ausentes de su vocabulario y su programa filosófico. En las argumentaciones ockhamianas, la articulación entre el aspecto crítico-dialéctico y el constructivo-propositivo es tal, que siempre el primero es más voluminoso y el segundo, más escueto y hasta lacónico en algunos puntos claves. Sin embargo, se reconoce que en teoría del discurso científico Ockham desarrolla un sistema altamente articulado, con la clara intención de reconstruir sobre bases no realistas el edificio entero del conocimiento. Para ello, recurre a una renovación de las teorías de la significación y la suposición, lo cual le permite tematizar de modo nuevo los aspectos semánticos, sintácticos y veritativos del lenguaje, y forja un novedoso concepto de lenguaje mental según el cual los conceptos son, ellos mismos, signos mentales naturales de los hechos externos. Así, el giro ockhamiano no sólo se produce en ontología y metafísica, sino también en la teoría de la significación de los nombres, en la manera de entender las operaciones mentales y los procedimientos de verificación del conocimiento científico. Para Ockham nada hay en la creación, sino sustancias y cualidades individuales, y signos universales en la mente y el lenguaje humanos, capaces de simbolizar o representar esas realidades o a sí mismos. Nada hay de universal en las cosas mismas, ni nada de relativo: "hombre" significa el conjunto de los hombres y nombres colectivos como "pueblo", "sociedad" o "ejército" también significan una pura pluralidad de individuos, sólo que connotando alguna ordenación entre ellos, (v. g., la dependencia de los soldados al general, sin que esa dependencia sea algo del ser mismo de unos o el otro). Sobre el corpus filosófico-teológico ockhamiano se puede consultar, tanto presentaciones de conjunto, con estructura y enfoque más bien clásicos ${ }^{3}$, como más bien monográficas o problemáticas ${ }^{4}$. 
$3 \mathrm{Si}$, a continuación, se repasan sintéticamente las tesis centrales de las obras eclesiológico-políticas a las que Ockham dedicó las dos últimas décadas de su vida, hay que señalar en primer lugar su reconocimiento del origen descendente del poder de Pedro. Esta tesis se ve contrapesada por la caracterización del poder petrino como una comisión esencialmente pastoral-espiritual, en abierta crítica a la tesis hierocrática de la plenitudo potestatis papal. En el poder del papa, según Ockham, no se incluye hacer absolutamente todo lo que permite la ley divina o natural: esto significa que en él no están contenidos, ni virtual ni actualmente -por lo menos, de modo regular, salvos los casos de necesidad-, múltiples derechos de propiedad y jurisdicción particulares y determinados, actuales e históricos. La razón es, en la justificación de Ockham, que esos derechos se remontan originalmente a instituciones igualmente positivas debidas a la pura voluntad humana y no a una ordenación divina, de modo que no están incluidos en la esfera del poder petrino. Ockham no niega que la Iglesia recibió de Cristo la forma de gobierno monárquica, por razones de utilidad, pero sostiene que no se trató de una monarquía tiránica, pues en los hechos de Cristo consta que éste respetó y no disminuyó derechos temporales previos a su llegada. Por otra parte, Cristo mismo renunció a ejercer dichos derechos: esto significa que mal puede serle prohibido a cualquier cristiano hacer lo mismo, es decir, practicar la renuncia a la propiedad argumenta Ockham, en defensa de la regla franciscana impugnada por el papa-. Inversamente, Ockham sostiene el origen remoto ascendente de los poderes que ejercen los gobernantes seculares: el de los príncipes y reyes, igual que el del emperador romano-germánico, legítimo sucesor del emperador de la antigua Roma, al cual Cristo reconoció. Idéntica tesis sostiene respecto de sus derechos de propiedad, pues afirma que ambos derechos se originaron, como se ha dicho, en ordenaciones positivas: su causa inmediata fue la sola voluntad humana de ejercer ciertas potestades o derechos que, según Ockham argumenta, son conformes a la razón y al mismo tiempo se entienden como habilitados por Dios en los textos revelados. La clave de todo el armazón teórico ockhamiano reside aquí: en esta distinción entre potestades o derechos dados "por Dios y la naturaleza" en común a toda la humanidad, pero de modo simplemente potencial, y derechos histórica y humanamente instituidos para actualizar esas simples potencialidades naturales. Fueron por derecho divino y natural (esto es, fundados en la Revelación y en la naturaleza), no los primeros gobernantes ni las primeras propiedades (por ende, tampoco los actuales), sino los derechos generales (por tanto, de fieles e infieles) a instituir rectores con jurisdicción temporal, a tener propiedades sobre los bienes temporales, en común o en particular, para asociaciones o para individuos, y a contraer matrimonio y derechos sobre los hijos. Estos derechos naturales se agregan o sobreañaden, después del pecado, al más básico y propio del estado paradisíaco: usar los bienes temporales para sustento y utilidad humanos. He aquí una apretada síntesis de las ideas eclesiológico-políticas de Ockham, para una exposición detallada de las cuales se puede consultar tanto libros clásicos ${ }^{5}$, como recientes ${ }^{6}$.

4 Por el anterior repaso ya se puede ver que el compromiso de Ockham con la causa antipapal de los franciscanos significó una ruptura neta con sus intereses anteriores: en sus obras filosófico-teológicas prácticamente no hay signo de preocupación por cuestiones como los alcances y límites de los derechos de propiedad y jurisdicción, el origen de la autoridad terrenal o celestialmente instituida, etc. Inversamente, y contra lo que cabría esperar, en sus obras eclesiológico-políticas hay escaso recurso a las argumentaciones metafísicas desarrolladas en la etapa previa. Con todo, como veremos, 
la historiografía de la primera mitad del siglo xx sobre el pensamiento político y social de la Baja Edad Media hizo, de la conexión entre su "metafísica del individuo" y su teoría de las instituciones, uno de sus temas favoritos.

\section{El estado de la cuestión}

5 El principal artífice de esta conexión fue Georges de Lagarde (1942-1946), constructor del gran relato del surgimiento del "espíritu laico" en la "declinación" de la edad media, en la famosa obra que lleva ese nombre y que sigue despertando admiración por la multiplicidad de fuentes que estudia y la ambición de reconstrucción holística del período. De Lagarde se basaba, a su vez, en Paul Vignaux, uno de los principales rehabilitadores de Ockham en los años ' 30 y 40', autor de la imagen general de un "Ockham metafísico" o del ockhamismo como una "metafísica del individuo" 7. Según esta perspectiva, aunque Ockham había rechazado lo que vulgarmente se llama "entidades metafísicas" -v.g., entidades universales existentes fuera del intelecto humano-, el hecho de que hubiera desarrollado una ontología alternativa centrada en el individuo concreto, desnudo de toda naturaleza o esencia, constituiría una metafísica en sí misma. La metafísica ockhamista del singular habría venido a oponerse, tanto a las metafísicas realistas extremas de cuño neoplatónico, como al realismo inmanentista aristotélico. La interpretación de de Lagarde comenzaba por buscar apoyo en la argumentada "unidad del ockhamismo" en cuanto al método, el lenguaje y estilo, la personalidad de su autor, su inspiración y sus principios ${ }^{8}$; continuaba reconstruyendo los principales temas de su metafísica ${ }^{9}$, para alcanzar su clímax en el estudio de la teoría de la relación y, más precisamente, de la "vida de relación" en los conjuntos sociales ${ }^{10}$. El punto crucial de la conexión metafísico-política residiría precisamente, según de Lagarde, en la teoría ockhamista de la relación como un puro signo o nombre para referirse a los individuos tomados en conjunto. La continuidad entre metafísica y filosofía política se extendería, según esta perspectiva, a los demás escolásticos de fines del siglo XIII y primeras décadas del xIV: desde el realismo escotista, pasando por el realismo moderado de Tomás de Aquino, Enrique de Gand, Godofredo de Fontaines y Pedro de Auriole, hasta el terminismo o nominalismo de Ockham, la teoría de la relación era vista, en todos los casos, como "puente" entre la metafísica y las "ciencias morales". La pintura trazada por de Lagarde constituía un relato de gran coherencia, para el cual se basaba en los grandes historiadores de su propia época. El realismo de la relación que habían asumido a principios del s. XIV los teólogos y los juristas (entre éstos, los legistas, con ayuda de los canonistas) había sido la herramienta teórica para formular, en términos abstractos, el modelo corporativista de organización social que se había ido conformando en la práctica, de modo accidentado y caótico, desde el siglo XII. Así, las teorías realistas de la sociedad como un cuerpo y una persona ficta o repraesentata de Enrique de Gand o Godofredo de Fontaines habrían elevado a términos teóricos el colectivismo o corporativismo cuya descripción ofrecía Pirenne ${ }^{11}$. Según éste, la corporación medieval de los siglos XII y xIII había sido el paradigma de una sociedad organicista, ejemplo perfecto de la comparación aristotélica entre la pólis y el panal: una organización social que daba clara prioridad al todo social sobre las partes; a la corporación, sobre los individuos y a la comuna o la colectividad, sobre las corporaciones ${ }^{12}$. Los teóricos de la sociedad entendida como un todo anterior a los individuos no habían hecho otra cosa que emplear los conceptos del aristotelismo que 
les resultaban útiles o adaptables para poder elevar a términos teóricos las prácticas corporativas que venían teniendo lugar en sus sociedades ${ }^{13}$. Análogamente, unas décadas después Ockham no había hecho otra cosa que condensar en términos teóricos el estado de fragmentación y descomposición de esas antiguas unidades y solidaridades. En suma, las teorías eran las prácticas preexistentes, elevadas a términos abstractos.

6 Este relato se percibe sustancialmente similar al de un clásico como la Historia del pensamiento político en la edad media de Walter Ullmann, cuyo principal interés era entender el fenómeno de lo que denominaba la "revolución aristotélica" en las últimas décadas del siglo xIII, es decir, el éxito teórico del aristotelismo político en los ámbitos académicos y gubernamentales, en reemplazo de los principios descendentes teocráticos que habían dominado hasta ese momento. Dicho éxito se explicaba, en el esquema ulmanniano, por prácticas preexistentes de los principios ascendentes de gobierno en las capas inferiores de la sociedad medieval, en la forma de asociaciones, corporaciones o gremios, en las comunidades locales y en las ciudades y ligas entre ciudades. El modelo aristotélico de comprensión de la sociedad humana, recién conocido de modo completo en los años 1260's gracias a la recuperación de la Politica, habría servido, según Ullmann, para plasmar en la teoría esas relaciones sociales preexistentes ${ }^{14}$. Del mismo modo, uno de los principales estudiosos de las formaciones corporativas medievales sostenía, para la misma época: "La importancia del movimiento asociativo en la edad media, lo extendido y el volumen de manifestaciones tan diversas por las cuales éste se presenta al historiador, son hechos bien establecidos desde hace largo tiempo. Al registrar su florecimiento en el siglo xIII hay que constatar también que él representa un elemento esencial de la mentalidad de los hombres de esta época: miembros de una comunidad aldeana, de la respublica de una ciudad italiana, de la universitas del reino inglés, de una humilde confraternidad, de una orden religiosa o de una de las grandes universidades de estudios, ellos no pueden hacer otra cosa que tomar conciencia de las solidaridades que los unen a sus hermanos, a sus colegas, a sus conciudadanos, del grupo que forman naturalmente todos juntos. He allí los lazos potentes que condicionan su actividad, imprimen una orientación a su existencia, sirven para fijar su lugar y sus prerrogativas u obligaciones en la sociedad. Hay en ese conjunto un elemento de gran valor en la constitución de la personalidad de cada uno al interior de la personalidad colectiva del grupo. Faltaba aún, sin embargo, algo para volver más intensa esa conciencia: es la posesión de una doctrina que permitiera profundizarla en el plano especulativo. Ese complemento iba a venir hacia los años 1260-1270 (...). (...) Es la doctrina de la sociedad humana, tal como la propondrá la Política de Aristóteles y la elaborarán los maestros de fin del siglo siguiendo a Tomás de Aquino: la doctrina de las comunidades jerarquizadas, desde la familia al Estado y la Iglesia; la del bien común del cual, en todos los estamentos, se benefician sus miembros, los cuales, sin embargo, deben defenderlo y promoverlo. (...) Si ha sido así, ¿no es debido al hecho de que la vida de las colectividades en el siglo xiII y la conciencia de la solidaridad que ellas habían dado a sus miembros eran la mejor preparación para comprender y edificar una filosofía social y política como la que se iba a constituir?" ${ }^{15}$. De modo coherente con este relato que cohesionaba fuertemente prácticas sociales $\mathrm{y}$ teoría, de Lagarde entendía que el "individualismo" o "anticolectivismo" de Ockham, unos años posterior, expresaba en términos teóricos la declinación de ese modelo social corporativo y el surgimiento de la sociedad tardomedieval, penetrada por los intereses 
particulares y las ligas o alianzas transversales entre grupos o estamentos, los cuales a su vez originarían los protoparlamentos europeos del Antiguo Régimen.

7 Ahora bien, así como de Lagarde se basó en Pirenne y von Gierke, así también, M. Villey se basó en De Lagarde para su célebre interpretación de la evolución de las ideas jurídicas europeas entre el Bajo Medioevo y la Modernidad ${ }^{16}$. Según la conocida interpretación de Villey, Ockham sería el destructor del "derecho objetivo", representado por la teoría aristotélico-tomista de la ley natural, y el heraldo de los llamados "derechos subjetivos" o individuales, típicos de la filosofía política moderna. La convicción sobre una conexión entre la metafísica y las ideas políticas ockhamistas yace a la base de esta interpretación. El estallido del orden cósmico en una pluralidad de átomos no podía tener otra consecuencia que el estallido de la ley natural universal en una pluralidad de derechos particulares. Se sabe que en la construcción del mito historiográfico general del s. XIV como "decadencia de la escolástica" y de Ockham como su principal figura, de los cuales Villey parece participar expresa o tácitamente, influyó de diversos modos el neotomismo contemporáneo. Nos gustaría, aunque no podemos, precisar si esta influencia puede proyectarse aún más atrás, a la conexión von Gierke - Pirenne - De Lagarde. Adivinamos que en el retrato de la organización corporativa del s. XIII como basada en un "sentimiento colectivo de unión" se esconde la admiración por un modelo social que aparentemente contenía y morigeraba los conflictos conservando fuertes jerarquías, a imagen del "corporativismo" que la Iglesia abrazó como su doctrina social desde León XIII.

Quienes defendían la continuidad o la conexión entre el pensamiento político de Ockham y su pensamiento filosófico-teológico tendieron a caracterizarlo como un innovador de tendencias "disolventes", un "revolucionario" y, más precisamente, un "imperialista", debido a su fuerte crítica de las ideas hierocráticas y su compromiso con Luis de Baviera. Pero esa lectura fue objetada ya tempranamente por quienes, con razón, hicieron énfasis en la impronta teológica del pensamiento político ockhamista y le atribuyeron, opuestamente, una tendencia conservadora: después de todo, Ockham volvía al modelo más bien tradicional (gelasiano) de la dualidad de poderes; refrendaba el fundamento revelado del primado petrino y no proponía mecanismos regulares de revocación del poder imperial. Estas discusiones derivaron en una tercera estrategia interpretativa que intentó superar esa controversia; se rechazó, en general, la pertinencia de la conexión entre la Opera Politica y la Opera Philosophica et Theologica (al menos, la "deducción" de la primera respecto de las segundas) y se entendió a Ockham como un "constitucionalista" liberal moderado, por su énfasis en el origen humano de los poderes y propiedades fácticos y por su teoría de la proprietas y la iurisdictio como derechos o poderes naturales de toda la humanidad, fiel o infiel. (Para una síntesis de las discusiones, con un intento de superar las antinomias ${ }^{17}$ ). El panorama interpretativo más reciente se reparte entre representantes actuales de esta última tendencia, que por lo general se concentran en el análisis de la teoría ockhamiana de los derechos "subjetivos", y otros que consideran necesario analizar el pensamiento político ockhamista enfatizando en su contexto polémico, es decir, en las alternativas de la querella sobre la pobreza entre el grupo de Miguel de Cesena y Juan XXII, y el conflicto entre dicho papa y el emperador romano-germánico Luis de Baviera ${ }^{18}$.

Los debates posteriores sobre el pensamiento político ockhamista inauguraron nuevos tópicos. Se discutió si se debía atribuir mayor o menor peso a la dimensión combativa de sus escritos: hay cierto consenso en que la temprana motivación personal de 
defender el modo de vida franciscano contra los ataques papales cedió paso a una preocupación más teórica por la sociedad cristiana y sus instituciones ${ }^{19}$; asimismo, se suele ver una serie de sucesivos giros en los intereses teórico-políticos de Ockham, desde la controversia de la pobreza hacia el problema de la herejía en general circa 1332-1334, de allí hacia el tema del poder papal en torno de 1337 y, por último, hacia el tema de la naturaleza del gobierno temporal en $1340^{20}$. En ese sentido, se ha discutido si hay mayor o menor continuidad entre sus obras políticas tempranas y tardías, y asimismo, a cuál de las diversas fuentes de las que se nutre el pensamiento eclesiológico-político de Ockham se debería atribuir mayor peso: sin duda, influyó en él la dialéctica del grupo de M. de Cesena contra las constituciones papales de Juan, pero ya no se considera el pensamiento eclesiológico-político de Ockham como un producto franciscano "químicamente puro" o representativo de esa tradición, así como no se lo considera creador del discurso sobre los derechos subjetivos, sino deudor de los canonistas ${ }^{21}$, y también se ha llamado a reconsiderar su recepción de la Politica ${ }^{22}$. Por fin, se ha discutido hasta qué punto se puede integrar en el pensamiento político personal de Ockham sus obras políticas reportativas, que formalmente sólo contienen una recensión de los debates de la época, sin que el autor haga explícito su compromiso con ninguna de las tesis u opiniones que reseña. Según cómo se evalúen estos diversos elementos, y conformemente a cierta proclividad de la historiografía de las ideas políticas (jcomo, quizá, de la política misma!) a polarizar los debates, Ockham puede ser visto como radical o como conservador, como apolítico o como imperialista, como ideólogo o como teórico abstracto.

10 Así las cosas, el problema de la conexión entre las ideas filosófico-teológicas y las eclesiológico-políticas en Ockham ha sido relegado a un lugar más bien marginal en los debates entre los intérpretes. Ciertamente, hay excepciones. Janet Coleman, una destacada estudiosa del pensamiento político medieval, ha enfatizado en la importancia del método y la epistemología desarrollados por Ockham en sus escritos filosóficoteológicos para la construcción de sus ideas sobre la sociedad y sus instituciones. "Algunos -dice- han argumentado que las dos fases de la vida de Ockham, primero como filósofo y teólogo académico de Oxford y después como teórico político exiliado en la corte de Baviera, produjeron dos conjuntos radicalmente inconmensurables de escritos que no pueden ser reconciliados. Algunos creen que su política no puede ser deducida de su lógica, filosofía y teología de Oxford. (...) Mi propósito aquí, sin embargo, es mostrar brevemente que sus distintivas posiciones lógicas, éticas y teológicas fueron fundamentales para sus posteriores y distintivas conclusiones políticas. (...) Mi objetivo es indicar que su teoría del conocimiento y su método para analizar los textos de la Escritura y la historia (el cual yace en su epistemología) fueron desarrollados en Oxford y duraron a lo largo de su vida cuando él respondió a asuntos y circunstancias cambiantes. Simplemente, su compromiso con la verdad ante la autoridad institucional se volvió crecientemente en foco. Es desafortunado que algunos historiadores del pensamiento político que están interesados en lo que se puede llamar la teoría política de Ockham hayan encontrado la epistemología de Ockham, y su lógica, tan difíciles como para ignorarlas" ${ }^{23}$.

11 Considerados estos tópicos, nos parece que sigue siendo difícil responder a estas preguntas: ¿fue, la filosofía nominalista, causante directa del nacimiento del individualismo jurídico y de la idea de que las entidades sociales, como tales, sólo tienen realidad ficcional, como suele decirse ${ }^{24}$ ? ¿Fueron las ideas de Ockham sobre la 
individualidad de lo real directamente operativas en sus ideas sobre los derechos de los súbditos y las totalidades sociales?

\section{Reconsiderando el problema}

12 Reconozcamos, como mínimo, que en la Opera Politica de Ockham ocupan un espacio abrumadoramente mayoritario las argumentaciones jurídicas, exegéticas y políticas, mientras que los argumentos o discusiones estrictamente filosóficos y teológicos (metafísicos, epistemológicos, etc.) aparecen muy sectorizada y marginalmente. Sin embargo, los argumentos metafísicos fueron frecuentes en las más diversas expresiones de la teoría política medieval, desde el naturalismo finalista de Tomás de Aquino al naturalismo necesitarista de Marsilio de Padua y desde el neoplatonismo papalista de Egidio Romano al neoplatonismo imperialista de Dante. Una clara economía de argumentos filosóficos o metafísicos en las obras eclesiológico-políticas de Ockham podría obedecer a una simple ruptura de intereses o, por el contrario, a una deliberada elusión de la especulación en temas prácticos y de autoridad. Es evidente que Ockham no contestó las profusas argumentaciones metafísicas de la hierocracia con argumentos de ese mismo estilo. Quizá esto se deba a que en los textos de sus enemigos ese tipo de argumentos no tiene demasiado protagonismo: la dialéctica de su interlocutor directo, Juan XXII, jurista de profesión, fue diferente, por citar un ejemplo, de la de un Bonifacio VIII, cuya famosa bula Unam Sanctam abundaba en argumentos organicistas, jerarquicistas u holistas, tomados, por ejemplo, del ps. Dionisio Areopagita. Debemos reconocer, en todo caso, que Ockham no usa (o al menos, no lo hace tanto como cabría esperar) sus propios argumentos filosóficos sobre la singularidad de lo real y el carácter puramente mental de los universales para defender el carácter puramente agregativo de todas las asociaciones, con las consecuencias que éstos podrían traer para deconstruir las jerarquías en los dos poderes. Nos atrevemos a decir que, si efectivamente los hubiera aplicado con toda la agresividad de la que había sido capaz en sus debates universitarios, probablemente su poder disolvente de las jerarquías y las estructuras de poder hubiera sido mayor: mucho mayor de lo que el propio Ockham deseaba. Acaso sea ésa una clave para explicar la sugestiva "desconexión" de la que hemos estado hablando.

13 Convendrá, con todo, detenernos en algunos de los casos excepcionales en que Ockham emplea un argumento metafísico para apoyar una conclusión política, y se trata, efectivamente, de la aplicación de su famosa teoría metafísica de la relación a la teoría de las corporaciones. Debemos, ante todo, precisar esa noción en la que de Lagarde vio el fundamento del concepto ockhamista de lo social. Como muchos otros temas filosóficos de la escolástica, se trató de un tema intensamente debatido por los intelectuales de la universidad medieval y, como casi todos ellos, fue un debate motivado por los textos de las llamadas "autoridades": principalmente, Aristóteles. El concepto de relación, que en latín se dice ad aliquid, relatio, respectus, habitudo, ordo, ordinatio y hasta aditas (la propiedad de ser "a", "para" o "hacia" otra cosa), era uno de los diez "géneros generalísimos", "predicamentos" o "categorías" bajo los cuales Aristóteles había clasificado el ser. Esta noción era una de las nueve categorías accidentales opuestas a la de sustancia. Como los autores medievales concordaron, al menos hasta muy entrado el s. XIII, en que cada una de esas categorías eran entidades metafísicas de algún tipo y que tenían naturaleza y estatus ontológico, hicieron lo 
propio con este particular predicamento, aunque Aristóteles hubiera dejado lugar a ciertos debates sobre su definición. En general, durante el siglo xIII hubo consenso mayoritario en que las relaciones no debían ser meros conceptos, sino que a nuestros conceptos relacionales (v. gr. "orden", "semejanza", "causalidad", "dominio", "paternidad") debía corresponderles algo en la realidad. Las cosas del mundo debían poder relacionarse independientemente de que las pensáramos como relacionadas -lo cual, en términos generales, podemos calificar como una concepción realista de las relaciones ${ }^{25}$.

Dentro de este escenario realista se abrieron dos tendencias. Una consideró a las relaciones como accidentes reales adicionales a los llamados accidentes absolutos o no propiamente relacionales: v.g., la semejanza entre Sócrates y Platón sería una propiedad real distinta de la blancura de Sócrates y la blancura de Platón, propiedad relacional que de algún modo vendría a añadírseles en el mismo momento en que devinieran relacionados, "enriqueciendo" su ser mismo. En el lenguaje medieval de la relación, por ejemplo, la proposición "Sócrates es semejante a Platón" se explica del siguiente modo: en virtud, o por causa de la blancura (el "fundamento"), la relación de semejanza inhiere en un sujeto (Sócrates) y "se termina" en otro ("Platón"). Asimismo, la relación de dominio inhiere en el señor por causa de la propiedad que se denomina potestas y "se termina" en el siervo ${ }^{26}$. Otra tendencia consideró, o bien que la relación es reductible a sus términos o relata (v. g., la "semejanza" se confundiría o identificaría con las cosas semejantes), o bien, que la relación no es propiamente nada del mundo real externo al intelecto humano, sino un concepto, término o signo mental que tiene la capacidad de significar de modo colectivo una pluralidad de individuos absolutos, externos al mismo intelecto. En la primera tendencia se ubicaron, entre otros, Alberto Magno, Tomás de Aquino y Duns Escoto; en la segunda, Ockham y los autores posteriores del siglo xIV que en general se conocen como "modernos" ${ }^{27}$. Con algunas oscilaciones entre las dos versiones mencionadas de esta segunda posición -las relaciones son las cosas mismas relacionadas o son conceptos que significan dichas cosas-, Ockham es claro respecto a considerar que en la realidad no hay más que cosas absolutas (v. g., Sócrates y su propia blancura, Platón y la suya), las cuales, como es obvio, de ningún modo son producidas por el intelecto ${ }^{28}$. Son esas cosas absolutas, y no terceras entidades intermediarias entre ellas, los significados de los conceptos relacionales. La noción ockhamista de relación se expresa, por ejemplo, así:

“(...) unitas universi est ordo partium ad invicem, (...) non quod ordo vel unitas sit aliquid in re distinctum ab omni parte et ab omnibus partibus universi. (...) nunquam ponenda est pluralitas sine necessitate" ${ }^{29}$.

“(...) dico quod vel similitudo est conceptus relativus significans plura coniunctim, vel est plura absoluta coniunctim. Sicut populus est plures homines et nullus homo est populus, ita similitudo est plura alba et nullum album est similitudo" ${ }^{30}$.

Uno de los pasajes en los que se considera que Ockham implica estas nociones se inscribe en su contestación a una de las constituciones antifranciscanas de Juan XXII. Contra éste, que se refería a la Orden Franciscana como una persona imaginaria, Ockham argumenta:

“...si Ordo Fratrum minorum est persona repraesentata et imaginaria, eadem ratione ecclesia et quaelibet communitas esset persona repraesentata et imaginaria, quod est absurdum, quod enim est tantum repraesentatum et imaginarium est fantasticum, et non est in re extra animam. Sed ecclesia non est quid fantasticum non existens extra animam, ergo non est persona repraesentata et imaginaria. Confirmatur: quia aut ecclesia est extra animam, aut in anima tantum, aut aliquid 
compositum ex ente in anima et ente extra animam. Si est in anima tantum, vel aliquid compositum ex ente in anima et ente extra animam, ergo nullum reale nec iurisdictionem realem potest habere: quae dicere de ecclesia est impium et blasphemum. Si autem ecclesia est extra animam vel ergo est una res, vel plures: et sive sit una sive plures, non est persona repraesentata et imaginaria. Ecclesia ergo non est persona repraesentata et imaginaria; et eadem ratione ordo Fratrum Minorum non est persona repraesentata et imaginaria" ${ }^{31}$.

Este pasaje sigue siendo citado para argumentar que en Ockham hay una conexión más bien estrecha entre su antirrealismo metafísico de los universales y las relaciones, por una parte, y un concepto estrictamente agregativo de toda comunidad humana, por otra. De esta forma, los intérpretes más renovadores coinciden con los antiguos tomistas. Claro que difieren de éstos en que eliminan la evaluación negativa del autor: rechazan que su intención fuera "destruir" la idea misma de cuerpo social o colectivo. Así, dice J. Coleman: “A diferencia de Marsilio, <Ockham> no cree que una colección de hombres en la corporación o el concilio general pueda asumir una personalidad separada que represente a sus miembros. Él tiene una teoría de las corporaciones, pero no es la teoría de la corporación representativa de su tiempo, como la que uno encuentra en los canonistas o en los escritos de Marsilio. La opinión colectiva puede ser sólo una suma de individuos dando su acuerdo a circunstancias presentes contingentes sobre la base de sus propias experiencias y pensamientos. Su corporativismo o conciliarismo es de la clase en que el todo es nada más que las decisiones de sus partes individuales respecto al bien común. Por eso, un concilio general no puede ser infalible (contra Marsilio). Según Ockham, cualquier todo es la suma de sus partes individuales, que desean lo que es para el bien público. Pero sus individuos no son átomos aislados. Ellos forman una comunidad en el sentido de un cuerpo concreto de individuos cuya unidad es lograda por el hecho de que ellos, razonando, llegan a la misma conclusión acerca de la utilidad común. <Ockham> no tiene una teoría del "estado" donde la autoridad pública, el oficio del gobernante, es una esfera separada y real de derechos propios bajo la ley. Trata al gobernante como un individuo, y trata la corporación de individuos, no como una persona creada (non est persona imaginaria et repraesentata), sino como una colección unificada de personas reales e individuales" ${ }^{32}$. En la misma línea, dice Mc Cord Adams: "Ockham no puede, consistentemente, ver las colectividades humanas (la sociedad o el estado) como sustancias aristotélicas, y una sustancia aristotélica no puede estar compuesta de muchas como ella. Es cierto que, en los escritos políticos, Ockham, en efecto, compara la sociedad con un cuerpo orgánico, y a su gobernante, con la cabeza. Pero la comunidad parece ser el concreto agregado de todas esas personas que pueden compartir mutuamente las cosas temporales por más distantes espacialmente que estén entre sí y ser un compuesto prepolítico cuya existencia e identidad son anteriores a toda forma de gobierno que se les imponga. Tales concretos agregados de individuos humanos serían, por supuesto, reductibles a los individuos de los que están hechos" ${ }^{33}$. Similarmente, Mc Grade argumenta contra el supuesto "individualismo" de Ockham en política, aunque considera que existe continuidad entre sus visiones políticas y sus teorías metafísicas y epistemológicas: “A veces se piensa que el nominalismo ve a los seres humanos como aislados entre sí de una manera distintivamente radical y por eso considera toda comunidad aparente como ilusoria. Por eso, antes de considerar cuestiones particulares sobre Ockham y la comunidad, se debe aclarar que tanto epistemológica como metafísicamente Ockham fue un vocero del comunitarismo" ${ }^{34}$. 
Creemos que, con todo, este pasaje puede ostentar aristas inadvertidas. Ante todo, que la noción de persona ficticia contra la que él argumenta había sido desarrollada por los juristas Baldo y Bartolo sobre la base de la teoría de las corporaciones de Inocencio IV y con algunos antecedentes en los decretalistas y los juristas Juan Basiano y Azo. Estos autores desdoblaban el estado, la ciudad y demás instituciones en un todo concreto compuesto de puros individuos, pero por eso mismo mortal y perecedero, y un todo puramente ficticio, captable por el intelecto, pero por eso mismo inmortal y duradero. Era esa segunda entidad, ese cuerpo místico o abstracto, el que constituía, propiamente, una persona jurídica, sujeto de derechos sobre el territorio y cuyo poder ejercía el gobernante. Mientras que los juristas más antiguos (v. g., los glosadores, como Acursio) identificaban las asociaciones con sus miembros, los posteriores sostenían esta nueva doctrina, base de la célebre teoría de los dos cuerpos del rey ${ }^{35}$ :

"Nec obstat quod glossa dicit(...)quod populus non est aliud quam homines, quia debet intelligi de hominibus collective assumptis, unde homines separati non faciunt populum, unde populus proprie non est homines, sed hominum collectio in unum corpus misticum et abstractive sumptum, cuius significatio est inventa per intellectum" ${ }^{36}$.

Parece claro que el rechazo de Ockham a que la orden o la Iglesia (y, presumiblemente, cualquier totalidad colectiva) constituyan personae repraesentatae o fictae implica un regreso a la concepción jurídica más antigua. Ockham aparecería como lo habían visto algunos intérpretes: como un deliberado "conservador", como si hiciera un gesto de voluntario regreso al pasado.

Diferenciándonos de las lecturas corrientes del pasaje, queremos explorar la posibilidad de que su posición tenga puntos de contacto con su posicionamiento filosófico en teoría del conocimiento, que se resume a continuación. En el marco de la recepción de variadas fuentes griegas y árabes, los escolásticos latinos habían desarrollado la teoría de la abstracción conceptual, que pretendía explicar, por una parte, la formación de los conceptos a partir de la inicial abducción de los datos sensibles, destinados a alojarse en el intelecto posible, a la manera de un archivo de nociones. Por otra parte, esta detallada psicología cognitiva se proponía explicar la diferencia entre esos conceptos en estado latente y la ejecución de actos mentales puntuales, fugaces y momentáneos. Para ello, se había utilizado la categoría de verbum, fictum, exemplar, ens rationis o ens repraesentatum. Cada vez que una mente concreta empleara los conceptos abducidos de la experiencia de modo actual, se formaría en el intelecto un "ser ficticio", un "verbo interior" universal, destinado a ser el término directo e inmediato del acto mental en cuestión. El objetivo último de esta teoría era explicar que las palabras dichas y escritas tenían por significado esas entidades mentales, en alusión a unas célebres palabras de Aristóteles según las cuales las voces significarían las pasiones del alma. Esos entes ficcionales servían, pues, para garantizar la estabilidad y universalidad de los significados de las palabras. La teoría del verbo mental había sido desarrollada por los seguidores de Tomás de Aquino a partir de bases teóricas sentadas por éste y continuaría siendo profundizada por Duns Escoto y los suyos ${ }^{37}$. Ockham adhiere tempranamente a esa teoría y en sus textos intermedios todavía la considera plausible:

“...posset poni (...) quod passiones animae sive intentiones animae sive conceptus

(...) tantum sunt quaedam cognita ab anima, ita quod esse eorum non est aliud quam ipsa cognosci; et possunt vocari idola secundum modum loquendi aliquorum vel quaedam ficta secundum modum loquendi aliorum" 38 . 
Posteriormente, en un giro que todos los intérpretes consideran radical y decisivo, Ockham elimina los pseudo-entes ficcionales y reduce los conceptos a actos mentales que significan directamente los individuos extramentales. Este giro tiene la importancia de eliminar los llamados "objetos intencionales" u "objetos inmanentes a la conciencia" como términos intermediarios entre la mente y las cosas. Así, Ockham llega a modelar su noción característica de los conceptos como puros actos mentales, concretos y particulares, con capacidad de significar directa y naturalmente las cosas individuales, rechazando las nociones de entidad representada, representación o fictum, que seguirían siendo operativas en las tradiciones tomista y escotista. El debate sostenido con Juan XXII acerca de si las corporaciones en general (tanto la Iglesia como la Orden franciscana) son entidades ficticias o imaginarias parece ser, así, terreno de repercusión del debate gnoseológico del que Ockham había participado en sus años previos. Lo que estaría en juego sería, más que una doctrina ontológica, un realismo gnoseológico transpuesto al plano jurídico. Contra este realismo gnoseológico, y no contra el realismo de la relación, estaría pronunciándose Ockham.

21 Cuáles son las implicancias propiamente jurídicas de este giro ockhamiano, no podemos, naturalmente, determinarlo sobre la base de este solo texto. Cabe, en los límites de este análisis, señalar, ante todo, que no hemos visto recogido este elemento de análisis por ninguno de los analistas del pensamiento ockhamiano. Por lo demás, que no fueron las ideas ockhamistas las que iban a triunfar, ni en gnoseología ni en teoría de las corporaciones: gracias al impulso del escotismo, las teorías representacionalistas del conocimiento iban a dominar la Modernidad temprana y la teoría jurídica de la persona ficta ayudaría a moldear el concepto moderno del Estado. En todo caso, lo que aportan estas precisiones sobre el vocabulario y el debate involucrados en el texto de Ockham es, al menos, algunas preguntas: ¿influyó la teoría de la representación conceptual en la teoría de la representación jurídica? Y si ello fue así, ¿fue su propio posicionamiento en materia de representaciones conceptuales el que llevó a Ockham a asumir su posición en el terreno de la representación corporativa? Como se ve, nuestro modesto aporte es resignificar, sobre la base de estas observaciones, la vieja pregunta sobre la conexión entre metafísica y política.

\section{Conclusión y perspectivas}

Rehusaremos pronunciarnos, dentro de los límites de este trabajo, sobre el significado del "antirrealismo" ockhamiano respecto de los conjuntos sociales, tanto seculares como espirituales. Creemos que el "gran relato" iniciado por el tomismo en el siglo xx respecto a la conexión entre metafísica de las relaciones y teoría de las relaciones colectivas permanece incuestionado en sus fundamentos. Como muestra, basta con ver que Marilyn Mc Cord Adams, autora del principal libro de conjunto sobre Ockham en la segunda mitad de siglo, reproduce ciertos lugares comunes al respecto: "En la teoría de los valores, la cuestión puede ser si los individuos son anteriores, no a los universales, sino a las colectividades, a la sociedad o el estado. Las posiciones van desde (lo que podemos llamar) Colectivismo extremo - que trata la sociedad o el estado como una sustancia aristotélica cuyo florecimiento constituye el telos normativo y cuyas partes orgánicas son individuos que derivan su esencia del todo y no pueden existir aparte de éste más que una mano aristotélica seccionada, del hombre- al Individualismo extremo que comienza con los individuos y sus deseos pre-sociales y deriva la autoridad y la 
competencia normativa del gobierno como una solución al problema de coordinación de la máxima satisfacción del deseo individual" ${ }^{39}$. Es interesante notar que el énfasis en la conexión entre la metafísica de la relación y la teoría de la sociedad ha atravesado los enfoques más diversos: no sólo fue suscripto por el tomismo ${ }^{40}$, sino también por otras escuelas que, a pesar de ser poco proclives a la especulación metafísica tradicional, establecían una fuerte continuidad entre la "metafísica antimetafísica" o "metafísica del singular" de Ockham y sus ideas eclesiológico-políticas. Por ejemplo, Largeault ${ }^{41}$, desde una explícita adhesión al liberalismo político y fundamentalmente económico, propuso una línea de continuidad directa de esa visión social con una filosofía singularista y anti-idealista, y sostuvo que Ockham había representado ambas vertientes en su expresión originaria. Esto podría indicar que el interés en la tesis de la continuidad entre ambas esferas interesaba en función de programas ideológicos: desde el de justificar un orden social conservador, presumiblemente vinculado a la doctrina social de la Iglesia, al de defender las teorías liberales sobre el interés y el beneficio social e individual.

Indudablemente, esos sesgos ideológicos pueden haber influido en la construcción del "gran relato" de la continuidad. Es hora de revisar la interpretación general según la cual, en la medida en que se asumiera una posición más o menos realista sobre el estatus metafísico de la relación, se vería la vida de relación, los conjuntos sociales, las comunidades de todo tipo (universitates), como esenciales o intrínsecas a los individuos, como "modalidades permanentes de su ser" -en el caso de las posiciones más realistas-, o como construcciones ficticias que no afectarían el ser intrínseco de las personas, consideradas absolutos independientes entre sí -en el caso de las posiciones más nominalistas-. ¿Por qué cuestionar esa visión de conjunto? Para empezar, porque el modo en que de Lagarde conectaba las teorías filosófico-jurídicas con las prácticas corporativas previas hacía invisibles las evidentes discontinuidades y conflictos entre ellas -por ejemplo, con la visión y la institucionalidad cristianas que indudablemente sustentaban a las segundas-. Si una discontinuidad tan manifiesta parece haber existido en ese terreno, ¿por qué no objetar igualmente la continuidad que de Lagarde establecía, desde Tomás de Aquino, pasando por los diversos "realistas moderados" y apuntando, como en línea recta, a Ockham? Parece, por ejemplo, que un autor como Pedro de Auriole es más tradicionalista que Ockham en el tema de los universales, cuya teoría del esse apparens es una forma de "representacionalismo" explícitamente criticada por Ockham ${ }^{42}$. Sin embargo, Auriole es más radicalmente nominalista que éste en el de las relaciones ${ }^{43} \mathrm{y}$, para colmar la aparente inconsecuencia, contra la presentación de de Lagarde, parece que traslada de modo más directo que Ockham las consecuencias de esta posición metafísica a la teoría de las asociaciones ${ }^{44}$. Lo que queremos decir es, sobre todo, que los autores medievales podrían ser vistos como menos férreamente continuistas en cuanto a sus posiciones metafísicas y políticas. Los compromisos coyunturales o, simplemente, las opciones y posicionamientos netamente políticos, pudieron influir en las ideas políticas de un autor más que sus presupuestos metafísicos o filosóficos. Creemos, por eso, que para tener un cuadro de situación más ajustado y preciso de la cuestión sería preciso estudiar las numerosas variantes de conceptualismo más o menos tímidamente realista que precedieron en pocas décadas, o incluso años, al más maduro nominalismo de Ockham (en autores como Auriole, Enrique de Harclay, Durando de St. Pourcain, Walter Burley y otros) y, seguidamente, las observaciones que esos autores pudieran hacer sobre las relaciones sociales, jurídicas, políticas, etc. 


\section{NOTAS}

1. Venerabilis Inceptoris Guillelmi de Ockham Opera Philosophica et Theologica ad fidem codicum manuscriptorum edita, Cura Instituti Franciscani Universitatis S. Bonaventurae, St. Bonaventure, New York, 1967-1984, 16 vols. (= OPh / OTh).

2. Guillelmi de Ockham Opera Politica, Offler et alii (eds.), Publications of the University of Manchester, 1940 / 1974.

3. P. AlfÉRI, Guillaume d'Ockham. Le Singulier, París, 1989 ; C. MICHON, Nominalisme. La théorie de la signification d'Occam, Paris, 1994 ; A. MAURER, The Philosophy of William of Ockham in the Light of its Principles, Pontifical Institute of Medieval Studies, Toronto, 1999.

4. C. PANACCIO, Le discours intérieur. De Platon à Guillaume d'Ockham, Paris, 1999.

5. A. S. MC GRADE, The Political Thought of William of Ockham. Personal and Institutional Principles, London, 1974.

6. E. PeÑA EGUREN, La filosofía política de Guillermo de Ockham. Relación entre potestad civil y potestad eclesiástica, Ed. Encuentro, Madrid, 2005 ; T. SHOGIMEN, Ockham and Political Discourse in the Late MiddleAges, Cambridge Studies in Medieval Life and Thought, New York, 2007 ; J. A. DE CAMARGO RODRíGUEZ DE SOUZA, As relacoes de poder na Idade Média Tardia. Marsílio de Pádua, Álvaro Pais e Guilherme de Ockham, EST, Porto Alegre, Univ. do Porto, Fac. de Letras, 2009.

7. G. DE LAgARDE, La Naissance de l'esprit laïque au déclin du Moyen Âge. Essais critiques sur les premières manifestations de la conscience laïque des États modernes, Paris, 1934-1946, vols. IVVI ; Id., vol. V, p. 35 ; P. VignauX, « Nominalisme ", Dictionnaire de théologie catholique, A. Vacant et alii (eds.), vol. XI, París, Letouzey \& Aney, cols. 876-9 vol. XI, Paris, cols. 718-784, 1931.

8. G. DE LAGARDE, ibid., p. 7-35.

9. Ibid. p. 36-188.

10. Ibid. p. 189-232.

11. G. DE LAGARDE, vol. IV, p. 161-209.

12. G. DE LAGARDE, vol. III, p. 150 et 257-263 ; Ibid. vol. IV, p. 67-159.

13. Ibid. IV, p. 161-209.

14. W. Ulmann, A History of Political Thought: the Middle Ages, Londres, 1965 (Cito por la trad. castellana: Ariel, Barcelona, 1999) ; Ibid., cap. VI, éd. 1999, p. 152-165.

15. P. MICHAUD-QUANTIN, «La conscience d'être membre d'une Universitas", in Miscellanea Mediaevalia 3 (1964), p. 13-14.

16. S. PIRON, «Congé à Villey ", in L'Atelier du Centre de recherches historiques, 01, 2008 [http:// acrh.revues.org/index314.html].

17. A. S. MC GRADE, The Political Thought..., op. cit. 1974.

18. S. TAKASHI, Ockham and Political..., op. cit. 2007.

19. A. S. MC GRADE, The Political Thought..., op. cit. 1974.

20. S. TAKASHI, Ockham and Political..., op. cit. 2007.

21. B. TIERNEY, The Idea of Natural Rights. Studies on Natural Rights, Natural Law and Church Law (1150-1625), Atlanta, Georgia, 1997.

22. M. GRIGNASCHI, (1971), «L'interprétation de la Politique d'Aristote dans le Dialogue de Guillaume d'Ockham », in AAVV, Liber memorialis Georges de Lagarde, Louvain/Paris, 1971.

23. J. Coleman, A History of Political Thought. From the Middle Ages to the Renaissance, Oxford, 2000, p. 170.

24. D. IognA-PRAT, La Maison Dieu. Une histoire monumentale de l'Église au Moyen Âge (v. 800-v. 1200), Paris, 2006, p. 485. 
25. J. B ROWER, "Medieval Theories of Relations", Stanford Encyclopedy. of Philosophy, 2008 in [http://plato.stanford.edu/entries/].

26. B. BERETTA, Ad aliquid: la relation chez Guillaume d'Occam, Fribourg, 1999.

27. A. J. KREMPEL, La doctrine de la relation chez saint Thomas. Exposé historique et systématique, Vrin, Paris, 1952, p. 245-271.

28. B. BERETTA, Ad aliquid: la relation..., op. cit., 1999.

29. оскНАM, Scriptum in librum primum Sententiarum ordinatio, dist. XIX-XLVIII, in G. ETZKORN, F. KELLEY, BROWN (éds.), Opera Theologica, vol. IV, St. Bonaventure, New York, 1979, p. 317.

30. оскнам, Summa Logicae, in P. Boehner, G. GÁL, S. Brown (éds.), Opera Philosphica vol. I, St. Bonaventure, New York, 1974, p. 639.

31. оскHAM, Opus nonaginta dierum, in SIKES, BENNETT, OFFLER (éds.), Opera Politica II, Manchester, 1940, p. 568.

32. J. Coleman, A History of Political..., op. cit. 2000, p. 180.

33. M. MC CORD ADAMS, "Ockham's Individualisms ", in W. vOSSENKUHL, R. SCHÖNBERGER (éds.), Die Gegenwart Ockhams, Weinheim, VCH, Acta Humaniora, 1990, p. 3-24 ici p. 13-14.

34. A. S. MC GRADE, "Right(s) in Ockham. A Reasonable Vision of Politics ", in MÄKINEN, VIRPI, KORKMAN, PETERS (éds.), Transformations in Medieval and Early-Modern Rights Discourse, Dordrecht, 2006, p. 63-94 ici p. 79.

35. J. H. BURNS (ed.), Cambridge History of Medieval Political Thought (=CHMPT), Cambridge, 2008.

36. Azo, ad C 7, 53, 5: 1498c, fol. 236r. Tomo la referencia de Burns, CHMPT, op. cit., p. 474.

37. C. PANACCIO, Le Discours Intérieur..., op. cit. 1999.

38. осКНАM, Scriptum in librum primum..., op. cit. 1979, p. 359.

39. M. MC CORD ADAMS, « Ockham's Individualisms », op. cit. 1990, p. 13-14.

40. A. J. KREMPEL, La doctrine de la relation..., op. cit. 1952, p. 610-635.

41. J. LARGEAUlt, Enquête sur le Nominalisme, Paris/Louvain, 1971.

42. C. Michon, Nominalisme..., op. cit. 1994.

43. J. J. BRower, « Medieval Theories...», op. cit. 2008.

44. M. GRIGNASCHI, L'interprétation de la Politique..., op. cit. 1971.

\section{ÍNDICE}

Mots-clés: Ockham, nominalismo, eclesiología

\section{AUTOR}

\section{CAROLINA FERNÁNDEZ}

Université de Buenos Aires, CONICET 